University of Nebraska - Lincoln

DigitalCommons@University of Nebraska - Lincoln

Educational Psychology Papers and

Publications

Educational Psychology, Department of

$5-7-2004$

\title{
Family-Centered Positive Psychology: Focusing on Strengths to Build Student Success
}

\author{
Susan M. Sheridan \\ University of Nebraska-Lincoln, ssheridan2@unl.edu \\ Emily D. Warnes \\ University of Nebraska-Lincoln \\ Richard J. Cowan \\ University of Nebraska-Lincoln, rcowan1@kent.edu \\ Ariadne V. Schemm \\ University of Nebraska-Lincoln \\ Brandy L. Clarke \\ University of Nebraska-Lincoln, brandy.clarke@unmc.edu
}

Follow this and additional works at: https://digitalcommons.unl.edu/edpsychpapers

Part of the Educational Psychology Commons

Sheridan, Susan M.; Warnes, Emily D.; Cowan, Richard J.; Schemm, Ariadne V.; and Clarke, Brandy L., "Family-Centered Positive Psychology: Focusing on Strengths to Build Student Success" (2004).

Educational Psychology Papers and Publications. 5.

https://digitalcommons.unl.edu/edpsychpapers/5

This Article is brought to you for free and open access by the Educational Psychology, Department of at DigitalCommons@University of Nebraska - Lincoln. It has been accepted for inclusion in Educational Psychology Papers and Publications by an authorized administrator of DigitalCommons@University of Nebraska - Lincoln. 


\title{
Family-Centered Positive Psychology: Focusing on Strengths to Build Student Success
}

\author{
Susan M. Sheridan, Emily D. Warnes, Richard J. Cowan, \\ Ariadne V. Schemm, and Brandy L. Clarke \\ University of Nebraska-Lincoln
}

\begin{abstract}
Family-centered positive psychology (FCPP) is defined as a framework for working with children and families that promotes strengths and capacity building within individuals and systems, rather than one focusing solely on the resolution of problems or remediation of deficiencies. This approach to family-based services is predicated on the belief that child and family outcomes will be enhanced if members participate in identifying needs, establishing social supports and partnerships, and acquiring new skills and competencies, rather than simply receiving services from professionals. In this article, we present a rationale for FCPP, outline its primary principles, highlight one model for working with families that exemplifies FCPP practice, and illustrate its use through an authentic data-based case study.
\end{abstract}

Positive psychology is defined as "the scientific study of ordinary human strengths and virtues," which "adopts a more open and appreciative perspective regarding human potentials, motives, and capacities" (Sheldon \& King, 2001; p. 216). Much of the literature on positive psychology focuses on the application of principles to the study of individuals in personal life contexts. Attention is provided to the attributes, capacities, and capabilities of the individual. For enhancing the lives of children, however, it is clear that similar strengths and assets must be garnered in the adults who control the environments within which all are interacting. That is, children and youth exist in interlocking contexts that both separately and together affect their functioning. The resources available to the adults who control those contexts are critically important for children's ultimate development. It has been argued that to truly help children, service providers must paradoxically focus efforts and energies on the adults (e.g., parents and teachers) in their lives (Conoley \& Gutkin, 1986; Sheridan \& Gutkin, 2000). Building strengths, enhancing skills, and coalescing resources for the multiple adults in children's lives are among the benchmark functions for school psychologists. Indeed, notions of positive psychology can be instrumental in our conceptualization of services provided to parents, family members, teachers, and other adults with whom children live. The purposes of this paper are to define family-centered positive psychology, identify its primary assumptions and key principles, present a model by which service providers (e.g., school psychologists) can use its principles to enhance outcomes for students, and illustrate the process with a case example.

\section{Definition and Assumptions of Family-Centered Positive Psychology}

For purposes of this paper, we define "family-centered positive psychology" (FCPP) as a framework for working with children and families that promotes strengths and capacity building within individuals and systems, rather than one focusing on the resolution of problems or remediation of deficiencies. The point of contact is the family as the context for growth within which children can develop competencies and capacities, given a focus on (and development of ) the family's strengths

Preparation of this article was supported in part by federal grant number H325D990010, awarded to the first author by the U.S. Department of Education. Opinions and ideas presented herein are those of the authors and do not reflect positions of the granting agency.

Correspondence to: Susan M. Sheridan, Department of Educational Psychology, 239 Teachers College Hall, University of Nebraska-Lincoln, Lincoln, NE68588-0345. E-mail: ssheridan2@unl.edu 
and resources. This framework represents a hybrid developed through the integration of concepts from ecological theory, family-centered services, and the helping/empowerment literatures.

FCPP is conceptualized as a means to an end, rather than an end in itself. The child is always at the center of services, and the "end" (or the primary goal) is enhanced outcomes for children and families. As suggested by Seligman and Csikszentmihalyi (2000), "promoting competence in children is more than fixing what is wrong with them. It is about identifying and nurturing their strongest qualities, what they own and are best at, and helping them find niches in which they can best live out these strengths" (p. 6). The manner in which this can be achieved most effectively involves working within the multiple social and ecological contexts within which children function, and which frame essential points of contact for services and service providers.

Ecological theory provides the conceptual vantage point for FCPP. Ecological theory is concerned with the multiple systems, environments, and contexts within which children function, and the interactions and interconnections among them. The primary, immediate systems (i.e., micro-systems) comprising the child's life are the home and school. Furthermore, the interconnections among these systems (i.e., the mesosystem) affect the child through relationships, communication patterns, and other bidirectional influences. The exosystem (e.g., events in settings in which the child does not directly participate) and macrosystem (e.g., the overall cultural or subcultural patterns and forces that subsume all other systems and subsystems) affect the child's development in more indirect but nevertheless pervasive ways (Bronfenbrenner, 1977).

Beyond the theoretical underpinnings of the model, elements of family-centered services (Dunst et al., 1988; McWilliam, Tocci, \& Harbin, 1998) provide a backdrop to FCPP. Family-centered services "place major emphasis on supporting and strengthening family functioning" in assessment and intervention (Dunst \& Deal, 1994; p. 73). Services are focused on assessing a family's needs and strengths from that family's perspective, with a positive and proactive rather than deficitbased approach.

\section{Key Principles of Family-Centered Positive Psychology}

Family-centered positive psychology is based on several premises or principles that together form the basis of service delivery. Ultimately, the dual goals of FCPP are family empowerment and enhanced functioning on the part of family members (including children). The key principles are listed in Table 1 and explored below.

FCPP is concerned with process as well as outcomes. As a process that promotes engagement, self-determination, and skill development, FCPP assists family members to actively participate in enhancing their own lives. Families are engaged proactively in identifying their own needs, mobilizing resources on their own behalf, and accomplishing self-determined goals through the development of personal capacities, strengths, and abilities. Through such processes, attainment of longterm, generalized positive outcomes is maximized.

Table 1

Key Principles of Family-Centered Positive Psychology

- Concerned with process as well as outcomes.

- Uses existing family strengths and capabilities to access and mobilize family resources.

- Focuses on family-identified rather than professional-determined needs.

- Promotes acquisition of new skills and competencies through specific types of helping behaviors and professional roles.

- Emphasizes strengthening social supports and networks. 
Although the attainment of both child and family goals are the outcomes of interest, it is the process by which professionals assist families (i.e., one that enables family members to continue garnering skills and capacities) that is the cornerstone of FCPP service delivery. Through the process of helping family members identify and prioritize needs, establish reasonable goals, and develop appropriate plans, opportunities for positive family outcomes (i.e., goal attainment) are maximized. Furthermore, strategies that are relevant and feasible for families, that result in desired outcomes, and that provide new knowledge and skill will likely be utilized again in the future when similar needs are present.

FCPP focuses on family-identified rather than professional-determined needs. FCPP is responsive to the needs of the client (i.e., family and child) and focuses assessment efforts on those needs that are most essential for the family to continue to grow. FCPP models assume that families are in the best position to identify their most salient needs, and commitment to change may be greatest when families' needs are self determined. Professionals are in a position to assist families with determining those needs that are most essential in attaining short-and long-term goals, and can use collaborative strategies to help discern immediate and proximal foci for intervention.

FCPP uses existing family strengths and capabilities to access and mobilize family resources. FCPP is founded on the belief that all families have strengths and abilities, but contextual or systemic conditions may present difficulties in accessing or using those strengths. The help-provider is in a position to help family members identify, access, and mobilize their strengths and use them to attain their self-determined goals. The ability of family members to use existing strengths for meeting their needs leads to positive changes in their functioning (Garbarino, 1982).

FCPP promotes acquisition of new skills and competencies through specific types of helping behaviors and professional roles. FCPP uses helping behaviors (professional roles) focused on developing capacities, based on an understanding and appreciation for "where the family is." Rather than utilizing strategies to "treat" problems or remediate deficiencies, FCPP approaches strive to promote the acquisition of family and child competencies. Models based on "correcting a problem" result in a limited, often short-term resolution of one presenting concern. Alternatively, FCPP attends proactively to growth-producing behaviors. The development of strengths, assets, and skills is expected to lead to generalization of resources to address a range of presenting challenges in the future. In sum, it is necessary but not sufficient to simply "solve" an identified "problem"; it is also necessary to provide assistance to a family so its members develop increased skills and resources.

Family-centered approaches to working with families promote "empowerment," which for purposes of this article is defined as a helping model that supports families in proactively identifying needs, mobilizing resources, and accomplishing goals through the development of personal capacities, strengths, and abilities. According to Dunst et al. (1988), "it is not just an issue of whether needs are met but rather that [sic] manner in which mobilization of resources and support occurs that is a major determinant of . . . empowering families" (p. 44). The emphasis is on family members' acquisition of competencies necessary for problem solution and goal attainment. A professional mindset that maintains self-as-expert and a goal of imparting knowledge and wisdom may lead to non-growth-producing outcomes. In a seminal text, Hobbs (1975) commented that "The foresighted professional person knows that it is the parent who truly bears the responsibility for the child, and the parent cannot be replaced by episodic professional service" (pp. 228-229). Furthermore, expert models of "helping" often lead to dependency on the professional, fail to produce personal resources and positive belief systems, and result in limited skills in assessing personal needs and mobilizing familial resources in the future.

The emphasis in FCPP is on strengthening social supports and networks. FCPP models are structured around intra-and intersystemic collaborations and partnerships that access formal and in- 
formal supports for family members. The development of positive, proactive linkages and networks help family members mobilize resources that are available to them but that may have been perceived as inaccessible. Furthermore, the notion of "partnership" implies that family members are co-equal partners in the identification of needs and goals, determination of strategies and plans, and evaluation of outcomes as programs and resources are utilized (Christenson \& Sheridan, 2001; Welch \& Sheridan, 1995). Thus, services are not delivered "to" or "for" families, but "with" family members as active partners and participants.

An essential system interacting with children and families is that of the school. Schools and classrooms represent significant contexts for development, and teachers are meaningful individuals in a child's life (Sheridan \& Gutkin, 2000). The establishment of partnerships between families and schools can be critical for maximizing the growth potential for a child. Positive, constructive relationships with other primary systems (i.e., schools) can be instrumental in helping families develop competencies and utilize resources on behalf of their child's development. Indeed, cross-system partnerships and the formation of relationships and support systems are key in FCPP (Dunst et al., 1988).

Although principles around family-centered services have been present for over a decade, specific evidence based models guiding practice are less prevalent. Conjoint behavioral consultation (CBC; Sheridan, Kratochwill, \& Bergan, 1996) is a model that has been developed with the goals of addressing children's needs, developing cross-system partnerships, and enhancing families' skills. This model will be reviewed next, with attention on its parallel to family-centered positive psychology. Finally, an authentic data-based case study will illustrate the principles and procedures of CBC from an FCPP perspective.

\section{Conjoint Behavioral Consultation}

\section{Definition, Process, and Conceptual Framework}

Conjoint behavioral consultation is defined as "a structured, indirect form of service-delivery, in which parents and teachers are joined to work together to address the academic, social, or behavioral needs of an individual for whom both parties bear some responsibility" (Sheridan \& Kratochwill, 1992, p. 122). In CBC, parents and teachers engage in a structured problem solving process with a consultant to collaboratively address the needs of children across home and school settings. Parents and teachers work together to share in the identification of needs for children and to develop, implement, and evaluate interventions to address those needs.

The CBC process consists of four stages, implemented in a collaborative manner. Three of the four stages are initiated in the context of a structured interview with parents and teachers. These include (a) conjoint problem identification, (b) conjoint problem analysis, (c) treatment implementation, and (d) conjoint treatment evaluation (Sheridan et al., 1996). During the conjoint problem identification interview, consultants work together with parents and teachers to identify a child's needs across the home and school settings, and consultees decide upon target behaviors for intervention. During this meeting, consultants also assist parents and teachers in identifying valid procedures for collecting baseline data on the target behaviors across settings. In the conjoint problem analysis stage of $\mathrm{CBC}$, parents and teachers evaluate the baseline data, decide upon behavioral goals for the child, and discuss various factors which may influence the child's behavior (e.g., events functionally related to the target behaviors). Hypotheses are generated regarding the environmental or functional conditions that may contribute to the occurrence of the target behaviors, and a plan is developed collaboratively to address the needs of the child.

The third stage of CBC consists of treatment implementation. During this stage, parents and teachers implement the intervention procedures in the home and school settings, supporting imple- 
mentation across settings. This stage does not involve a structured interview; however, the consultant remains in close contact with parents and teachers (e.g., phone calls and personal visits) throughout implementation of the intervention to provide support, ensure understanding of the plan, offer assistance, reinforce parent and teachers' intervention efforts, and determine the need for any immediate plan modifications. The final stage of $\mathrm{CBC}$ is conjoint treatment evaluation. During this stage, parents and teachers examine the behavioral data collected to evaluate the effects of the treatment and determine if the goals of consultation have been met across the home and school settings. The team discusses plans for continuation, modification, or termination of the intervention based on the child's progress towards his or her goal.

$\mathrm{CBC}$ acknowledges that children function within and across various systems in their environment by adopting an ecological-systems perspective (Bronfenbrenner, 1977; Sheridan et al., 1996). The two primary systems in children's lives are the home and school systems. CBC recognizes that children, families, and schools have a bidirectional, reciprocal influence over each other, and that the connections between home and school systems are essential for facilitating positive outcomes for children. $\mathrm{CBC}$ secures these connections by bringing together families and schools in a supportive and collaborative manner to address the needs of children. The process of $\mathrm{CBC}$ acknowledges the vital role played by families in children's education and includes families as equal participants in the problem solving process.

\section{Goals of $C B C$}

The $\mathrm{CBC}$ process described above provides a logical format for operationalizing the principles of family-centered positive psychology (FCPP), as the goals of CBC directly address these important principles. Important goals of $\mathrm{CBC}$ include (a) address the needs that consultees have for children, (b) establish partnerships, and (c) develop and enhance the skills and competencies of consultees (Sheridan et al., 1996). These goals parallel several FCPP principles, including (a) focus on family-identified rather than professional-identified needs, (b) strengthen social supports and promote partnerships and collaboration among systems, and (c) promote acquisition of family and child competencies (Dunst, Trivette, \& Deal, 1994; Dunst \& Trivette, 1987). The relevant CBC goals and FCPP principles are described below.

CBC goal: Address the needs that consultees have for children. The primary goal of CBC is to effectively address the needs that consultees have for children. These needs comprise the focus of consultation and are the basis for the services provided across settings. To effectively address the needs of consultees in consultation, consultants utilize two FCPP principles: (a) look to families to determine and define the needs and focus of consultation services, and (b) utilize existing family strengths and capabilities to meet these needs. CBC consultants do not make assumptions regarding the needs of families (i.e., the focus of consultation services); rather, they provide opportunities for families to voice their concerns and determine mutual goals with teacher consultees. This is the central objective of the conjoint problem identification stage of CBC.

As described above, consultants provide an opportunity for families to describe and prioritize their needs, thus ensuring that the greatest need is addressed in consultation. In this way, the needs addressed in $\mathrm{CBC}$ are those that are most central to families, thus increasing the probability that families will devote their resources of time and energy to data collection, plan implementation, treatment evaluation, and maintenance and generalization procedures. Consultants also incorporate a measure of flexibility in the process of prioritizing a behavior for data collection and intervention. For example, through data collection, consultees may learn that the initial needs were misidentified, and identify new, socially valid priorities later in the $\mathrm{CBC}$ process. This flexibility helps to ensure that the needs of the consultees and the child are met. 
Similarly, the consultant incorporates flexibility in developing interventions and data collection methods used throughout the $\mathrm{CBC}$ process, helping families determine those that fit within their environment. Successful data collection is more likely to occur if the consultant and the consultee develop an effective, practical, and efficient method of information gathering that fits within the consultees' routine. The same principle applies to selecting and implementing an intervention. The likelihood that families will feel both comfortable with and empowered by implementing a plan for their child increases as the plan matches the schedule and culture of the family.

Consultants encourage families to assess the various factors that may contribute to or influence the target behaviors of consultation primarily in the conjoint problem analysis stage of CBC. This analysis not only allows the consultation team to examine various familial factors that contribute to children's behavior (e.g., negative interactions with the child, ineffective routines, and/ or lack of resources), it allows for an examination of family competencies and strengths that can be used to address the needs of children. In CBC, consultants acknowledge that, just as teachers have expertise in educational interventions and managing classroom behavior, families have expertise relevant to the home environment. Families have skills and resources (e.g., supports in the home, interactions with children, knowledge of developmental history) that can be used to address children's needs in consultation. Consultants identify and further develop families' strengths throughout the consultation process, which contributes to intervention development. For example, the consultant may assess and highlight intervention procedures that families are already using throughout their daily routines. Highlighting the family's existing strengths in the home setting provides a sense of self-efficacy for consultees by acknowledging their abilities to effect positive change in their child's life (Dunst et al., 1988).

Rather than focusing on families' lack of resources to cope with or effectively manage their children's behavior, $\mathrm{CBC}$ consultants provide an atmosphere that supports families and allows their existing strengths to set the foundation for the problem solving process. Such a strength-based approach ensures that the focus of consultation is on families' capabilities rather than on what is lacking in parenting skills and resources. Building on existing family strengths is essentially a matter of "meeting the family where they are" (Dunst et al., 1988) and viewing family members as having strengths to be utilized to address the child's needs. In this way, consultants provide helping services that are congruent and consistent with consultees' needs.

$C B C$ goal: Establish partnerships. Strengthening social supports and promoting partnerships and collaboration among systems is an important principle outlined in FCPP (Dunst \& Trivette, 1987). CBC's goal of establishing home-school partnerships directly addresses this principle. Grounded in ecological theory, CBC attends to children's mesosystems (i.e., the relationships between settings that directly affect children; Bronfenbrenner, 1977; Sheridan et al., 1996). In CBC, home and school systems are collaboratively involved in a problem solving process to address mutual goals for children. This process allows schools and families to share in decision-making and adopt equal responsibility for both the needs assessment and solution development in CBC. Likewise, parents and teachers actively participate in data collection procedures and implementation of the interventions developed in $\mathrm{CBC}$.

As a team, consultants and consultees examine and evaluate behavioral data to verify the nature and extent of children's needs. The consultant facilitates the process but ensures that the teacher and parent jointly determine the goal and develop and implement the plan for the child. The teacher and parent collaboratively decide upon an acceptable level of the target behavior in both the home and school settings. Agreeing upon a behavioral goal requires that consultants encourage team members to look beyond what they "would like to see" (i.e., an ideal) versus a level of the behavior that will ensure initial success for the child. It is essential that the CBC process focus on realistic expectations for the child to help ensure that intervention results in positive outcomes (Dunst et al., 1988). 
General agreement among the home and school systems regarding a shared goal for consultation helps ensure continued partnership between primary caregivers (i.e., parents and teachers) in the child's primary social support systems (i.e., the home and school).

Individuals in the home and school systems gain mutual respect and trust for one another by working collaboratively through the $\mathrm{CBC}$ process. Home-school partnerships are formed that establish the foundation for future collaboration and problem solving to occur, as parents and teachers learn the benefits of working together to address children's needs. By establishing working partnerships, CBC strengthens the relationships between social support systems and promotes the immediate and future success of children and their families.

$C B C$ goal: Develop and enhance the skills and competencies of consultees. Consistent with the principle of family-centered positive psychology that seeks to promote the acquisition of family and child competencies, CBC aims to promote the skills and knowledge of families (Dunst et al., 1994). The CBC process achieves this goal through supporting and guiding the families' engagement in the problem solving process. As discussed above, families and schools are engaged in a structured problem solving approach to address the needs of children in CBC. In doing so, parents and teachers gather essential knowledge about aspects of the process such as the importance of identifying and defining the child's or families needs, assessing factors which may contribute to maintenance of a specific behavior, and developing interventions to address these influential factors.

Through the CBC process, families learn to prioritize their behavioral concerns for children. During problem identification, consultants help consultees identify specific behaviors to target for intervention, allowing for a more focused approach to problem solving. Likewise, detailed strategies for monitoring and evaluating target behaviors are discussed (i.e., methods of data collection and evaluation). Throughout the consultation process, parents and teachers collect data on levels of the target behavior(s) over time, as well as information regarding antecedent, consequent, and other environmental conditions that affect them. Consultants assist consultees in using this information to develop meaningful interventions that address children's needs. Similarly, behavioral data are used to develop socially valid goals for children and monitor behavioral progress. Through continued assessment of the behavioral data throughout the consultation process, consultants provide consultees with an understanding of the data based decision-making process. Consultees learn strategies for determining if goals have been met based on existing data, rather than subjective accounts of child behavior. Additionally, team members learn procedures for developing plan modifications when behavioral goals are not met. Through this process, families learn the value of using functional and behavioral data to guide decision-making regarding the child's progress and the efficacy of the intervention.

Each of the aforementioned skills developed through participation in the CBC process provides families with tools that can be used to address future family needs. Families are empowered by recognizing their existing competencies, strengthening their skills, and acquiring tools for independence, which lessens their dependence on professionals for assistance in the future. The CBC process and related FCPP principles are illustrated in the following case study.

\section{Case Study}

\section{Background Information}

Brandon was a four-year-old Anglo-European male attending an Early Childhood Special Education (ECSE) program housed within a suburban elementary school. He lived with his parents in 
a middle-sized midwestern city. Brandon was described as a medically fragile infant. At age three, Brandon was assessed and verified eligible for ECSE services as a child with a developmental delay, speech impairment, and orthopedic impairment. Medical complications considered for eligibility included premature birth, a G-button for feeding, and a brain shunt. Assessment conducted using the Bayley Scale of Infant Development indicated Brandon to be performing at the 12-13 month level of overall development. He received an Adaptive Behavioral Composite Standard Score of 52 (average $=100$ ), which placed him in the "significantly below average" level of functioning.

Brandon was referred for consultation by Ms. Roper, his ECSE teacher, for concerns regarding tantrumming. The consultation team consisted of Mrs. Smith (his mother), Ms. Roper, and Ms. Cook ( $\mathrm{CBC}$ consultant). The team engaged in the Conjoint Behavioral Consultation process described above, meeting a total of four times over the course of four months. For purposes of CBC, "tantrumming" was defined as, "When entering a large group or novel setting, Brandon exhibited physical changes in his body and voice, including a rigid body and raised voice; he also turned his body away, left the setting, and screamed, cried, or lied on the floor." Mrs. Smith reported similar concerns in the home and outside settings (e.g., grocery store).

\section{Illustration of FCPP Principles}

Focuses on family-identified rather than professionally determined need. As the team explored behavioral concerns across settings, Mrs. Smith reported that focusing on tantrumming would allow her and Brandon to lead more "normal" lives. Specifically, she indicated her desire to be able to take Brandon to the store and run errands that were an essential part of their daily routine, without his disruptive tantrums. Although Brandon had received extensive support through his Early Childhood Special Education program, it appeared that such resources had been less readily available to Mrs. Smith as a parent who expressed her desire to learn more about behavior management strategies. Further, Mrs. Smith reported that there were times when she did not use behavior management techniques (e.g., time out, ignoring tantrums) because of her son's medically fragile status. In response to this family's specific needs, the team identified the CBC process as an opportunity to help Mrs. Smith achieve success in managing her son's behavior, while at the same time targeting a behavior (i.e., tantrumming) across settings that would help him become more successful in a kindergarten classroom.

Early in the CBC process, Mrs. Smith also indicated a need that in order for her to be able to participate fully (a) data collection procedures would have to be simple, and (b) intervention procedures would have to be easy enough for her to implement independently, without the support of others (i.e., she was the primary caregiver and would be the only treatment agent in the home and outside settings). Through open communication, combined expertise, and shared ownership, the team was able to meet these prerequisites.

Uses existing family strengths and resources. Brandon's educational team demonstrated expertise regarding the education and development of children who are medically fragile. Mrs. Smith demonstrated that she possessed expertise regarding her son's psychological and medical history. Likewise, she was open to suggestions, and was willing to devote her time and resources to helping him achieve success across settings.

With a great deal of input from both Brandon's teacher and mother, the CBC team developed an observation system that could easily be used across settings (i.e., monitoring the duration of each tantrum). Derived from baseline data, the team established the goal that each occurrence of a tantrum would last no longer than three minutes. During the baseline data collection phase, Ms. Roper observed that, although tantrums were predicted due to the novelty and heightened activity of the kindergarten setting (as compared to his smaller preschool classroom), Brandon was able to remain 
in this novel setting without tantrumming. Given this observation, the team decided to focus intervention on the home and outside settings (e.g., free time at home, the grocery store), while at the same time continuing to expose Brandon to the kindergarten classroom regularly as a means of preparing him for his transition into kindergarten.

The intervention was comprised of two major components: (a) antecedent control and (b) differential reinforcement. Using resources available at home and school, antecedent control was achieved by providing Brandon with at least two choices from which he could select during times when tantrums were likely to occur (e.g., when selecting a free-time activity at home). Brandon was provided with an object to attend to (e.g., a watch) prior to entering a setting likely to evoke a tantrum (e.g., walking into a store). When Brandon tantrummed as the result of either a choice he made (e.g., selecting a particular video at home) or being exposed to a new setting (e.g., going to a new store in the mall), he was ignored. When Brandon responded appropriately (i.e., did not tantrum) to a choice he had made or when exposed to a novel or undesired environment (e.g., the grocery store or the kindergarten classroom), he was reinforced through verbal praise and tactile stimulation (i.e., tickling his upper body).

Strengthens social supports to promote partnership and collaboration among systems. Both Mrs. Smith and Ms. Roper reported that while in the past they had shared information about Brandon's performance across settings, they had not been afforded the opportunity to engage in joint problem solving. That is, until participating in the CBC process they had merely talked about behavioral concerns across settings, without exploring potential solutions. Mrs. Smith voiced admiration for Ms. Roper's command of the classroom and her successes in managing Brandon's behavior in multiple settings, and Ms. Roper expressed an appreciation for Mrs. Smith's willingness to implement new behavioral intervention strategies. As they worked toward a common goal (i.e., decreasing tantrum duration), their interactions became more proactive and appeared to resemble true partnership.

Promotes acquisition of family and child competencies. In an effort to develop and enhance the skills and knowledge of the consultees, the consultant overtly described and highlighted the CBC problem solving process as it occurred. The consultees learned about data-based decision making through allowing the data to guide the problem solving process. In addition to the above described interventions used to help Brandon achieve success across settings, consultation resulted in a portfolio of interventions and related materials Mrs. Smith could use with Brandon should his tantrums return to baseline magnitude. Additionally, Mrs. Smith and Ms. Roper met on occasion to plan for Brandon's transition into a new school for kindergarten. The objective of these meetings was to facilitate a smooth transition for Brandon and his mother by planning and establishing contact with future educational team members to discuss strategies to help him achieve success in the kindergarten classroom.

\section{Outcomes}

Behavioral data indicate that the team successfully met their behavioral goal that tantrums would last no longer than three minutes (see Figure 1). Self-report data were collected via Goal Attainment Scaling (GAS; Kiresuk, Smith, \& Cardillo, 1994) and a revised version of the Behavioral Intervention Rating Scale (BIRS; Von Brock \& Elliott, 1987). Goal Attainment Scaling was used to assess the parent's and teacher's perceptions of the attainment of consultation goals on a scale of "2" (situation became significantly worse) to " +2 " (goal completely met). Both Mrs. Smith and Ms. Roper reported a " +2 " rating, indicating that the behavioral goal was fully met across settings. The revised version of the BIRS (BIRS-R; see Freer \& Watson, 1999 and Sheridan \& Steck, 1995, regarding the psychometric soundness of the revised instrument) was used to assess the consultees' 


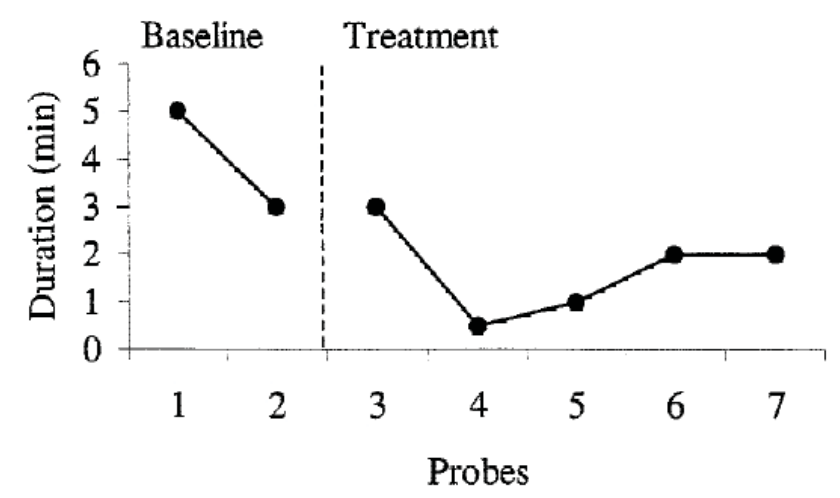

Figure 1. Brandon's baseline and treatment behavioral observation data in the home setting.

perceptions of CBC acceptability and efficacy. Mrs. Smith's home BIRS-R Acceptability factor rating was 5.9 (highly acceptable) and the BIRS-R Effectiveness rating was 5.0 (effective). Ms. Roper's school BIRS-R Acceptability rating was 5.8 (highly acceptable) and the BIRS-R Effectiveness rating was 4.9 (effective). These data indicate that both consultees found the $\mathrm{CBC}$ process to be an acceptable and effective means of addressing Brandon's needs.

\section{Summary}

Family-centered positive psychology (FCPP) represents a marriage of two important developments in psychology and the human services profession: positive psychology and family-centered services. It blends the philosophical advances of positive psychology with the pragmatic approach of family-centered services and provides fertile ground for future research. The purpose of this article was to present FCPP as an important direction in both areas, and to present a structured, empirically supported model of service delivery (conjoint behavioral consultation) within the framework of FCPP.

Although the premises and rationale for FCPP appear clear, research is needed to fully understand its utility. Whereas several studies have demonstrated support of CBC as an effective means of addressing clients' needs, its implementation within the FCPP framework has not been investigated. Furthermore, specific effects on parents' skills and competencies (one of the primary goals of FCPP) have not been investigated. Whereas parents routinely report satisfaction with consultants and acceptability of the model (see Sheridan, Eagle, Cowan, \& Mickelson, 2001 for a large scale study), their specific impressions and self-reported experiences of the model have not been questioned. Finally, it is possible that some families may benefit to a greater degree using an FCPP approach than others. Additional research may begin to investigate familial, contextual, or systemic factors that may predict outcomes differentially.

\section{REFERENCES}

Bronfenbrenner, U. (1977). Toward an experimental ecology of human development. American Psychologist, $32,513-529$.

Christenson, S.L., \& Sheridan, S.M. (2001). Schools and families: Creating essential connections for learning. New York: Guilford Press.

Conoley, J.C., \& Gutkin, T.B. (1986). Educating school psychologists for the real world. School Psychology Review, 15, 457- 465. 
Dunst, C.J., \& Deal, A.G. (1994). A family-centered approach to developing individualized family support plans. In C.J. Dunst, C.M. Trivette, \& A.G. Deal (Eds.), Supporting and strengthening families: Methods, strategies, and practices (pp. 73-88). Cambridge, MA: Brookline Books.

Dunst, C.J., \& Trivette, C.M. (1987). Enabling and empowering families: Conceptual and intervention issues. School Psychology Review, 16, 443- 456.

Dunst, C.J., Trivette, C.M., \& Deal, A.G. (1988). Enabling and empowering families: Principles and guidelines for practice. Cambridge, MA: Brookline Books.

Dunst, C.J., Trivette, C.M., \& Deal, A.G. (1994). Enabling and empowering families. In C.J. Dunst, C.M. Trivette, \& A.G. Deal (Eds.), Supporting and strengthening families (pp. 1-11). Cambridge, MA: Brookline Books.

Freer, P. \& Watson, T.S. (1999). A comparison of parent and teacher acceptability ratings of behavioral and conjoint behavioral consultation. School Psychology Review, 28, 672- 684.

Garbarino, J. (1982). Children and families in the social environment. New York: Aldine.

Hobbs, N. (1975). The future of children: Categories, labels, and their consequences. San Francisco: JosseyBass.

Kiresuk, T.J., Smith, A., \& Cardillo, J.E. (Eds.) (1994). Goal attainment scaling: Applications, theory, and measurement. Hillsdale, NJ: Lawrence Erlbaum.

McWilliam, R.A., Tocci, L., \& Harbin, G.L. (1998). Family-centered services: Service providers' discourse and behavior. Topics in Early Childhood Special Education, 18, 206-221.

Seligman, M.E., \& Csikszentmihalyi, M. (2000). Positive psychology. American Psychologist, 55, 5-14.

Sheldon, K.M., \& King, L. (2001). Why positive psychology is necessary. American Psychologist, 56, 216 217.

Sheridan, S.M., Eagle, J.W., Cowan, R.J., \& Mickelson, W. (2001). The effects of conjoint behavioral consultation: Results of a 4-year investigation. Journal of School Psychology, 39, 361-385.

Sheridan, S.M., \& Gutkin, T.G. (2000). The ecology of school psychology: Examining and changing our paradigm for the 21st Century. School Psychology Review, 29, 485-502.

Sheridan, S.M., \& Kratochwill, T.R. (1992). Behavioral parent-teacher consultation: Conceptual and research considerations. Journal of School Psychology, 30, 117-139.

Sheridan, S.M., Kratochwill, T.R., \& Bergan, J.R. (1996). Conjoint behavioral consultation: A procedural manual. New York: Plenum Press.

Sheridan, S.M., \& Steck, M. (1995). Acceptability of conjoint behavioral consultation: A national survey of school psychologists. School Psychology Review, 24, 633- 647.

Von Brock, M., \& Elliott, S.N. (1987). Influence and treatment effectiveness information on the acceptability of classroom interventions. Journal of School Psychology, 25, 131-144.

Welch, M., \& Sheridan, S.M. (1995). Educational partnerships: Serving students at risk. San Antonio, TX: Harcourt Brace. 